\title{
In-Flight Radiation: Counseling Patients About Risk
}

Robert J. Barish, $P b D$

Background: At the high altitudes, which are the domain of commercial airliners, cosmic-ray exposure rates are hundreds of times greater than at ground level. If this radiation originated at a regulated industrial or medical facility, many frequent flyers would receive annual exposures in excess of the present legal limit applicable to members of the public. For pregnant travelers, the fetus is also at risk, with a sensitivity that varies during the course of pregnancy.

Metbods: Health risks from in-flight radiation exposure are analyzed specifically to calculate the likelihood of cancer, birth defects, and genetic damage. A literature review was conducted from 1985 to 1998, using the key words "cosmic radiation," "aviation medicine," "radiation risk," and "in-flight radiation."

Results and Conclusions: The analysis shows that for the passenger who travels only occasionally, the risks are extremely small. For business frequent flyers the risks are still small, but not negligible. (J Am Board Fam Pract 1999;12:195-9.)

From the moment of conception every person on this planet is continuously exposed to background radiation. ${ }^{1}$ In addition to emissions from trace amounts of radioactive minerals that are present in soil and internal exposure from small amounts of radioactive substances that make their way into food and become incorporated into the body's cellular structure, there is a third component of background radiation that originates from the sun and other stars in our galaxy. This cosmic radiation is an energetic mixture of particles and electromagnetic waves.

The atmosphere of Earth provides a good shield against cosmic ray exposure. With increasing altitude, however, the shielding effect of the atmosphere is diminished until, at airliner flight altitudes, exposure rates become several hundred times greater than at sea level. ${ }^{2,3}$

Cosmic rays are ionizing radiation, which means they are energetic enough to disrupt the cellular structure in the body and potentially have an impact on the health of the exposed person; if that person is pregnant, the developing fetus can be affected, too. The most serious risk to an adult is the initiation of cancer. Fetal risks include birth defects and mental retardation. A third risk is genetic damage, which might appear as a birth defect in a child conceived some time after the par-

Submitted, revised, 7 October 1998.

From The Cancer Institute, Catholic Medical Centers of Brooklyn and Queens, Jamaica, New York. Address reprint requests to Robert J. Barish, PhD, In-Flight Radiation Protection Services, 211 E 70th St, Suite 12G, New York, NY 10021. ent's radiation exposure. ${ }^{4}$ Airline crew members flying long-haul high-altitude routes receive, on average, greater exposures each year than do radiation workers in ground-based industries where radioactive sources or radiation-producing machines are used. ${ }^{5}$ Passengers are exposed to cosmic radiation in exactly the same way as the crew members with whom they travel.

\section{Methods}

In this article I have analyzed health risks from inflight radiation exposure specifically to calculate the likelihood of cancer, birth defects, and genetic damage. Trained as a radiologic physicist, I have been involved in the science and politics of inflight radiation exposure for more than 10 years as an advocate for flight attendants and pilots, who need to understand these issues but who have not been fully informed about them by their employers, the airlines. I draw on training that enables me to understand the technical aspects of cosmic-ray dosimetry and measurement instrumentation, three decades of experience in the medical environment dealing with both patients and physicians, and an up-to-date extensive literature review using the following key words: "cosmic radiation," "aviation medicine," "radiation risk," and "in-flight radiation."

\section{Radiation Exposure Limits}

Low-level radiation has been studied extensively with respect to its effects on human health. The risks of the somatic and genetic effects of radiation 
have been published by such organizations as the United Nations Scientific Committee on the Effects of Atomic Radiation ${ }^{4}$ and the National Academy of Sciences-National Research Council. ${ }^{6}$ Much of the data come from continuing monitoring of the survivors of the atomic bombings of Japan in 1945, specifically a life-span study involving almost 80,000 persons. $^{7}$

Most experts in the field of radiation research agree that there are no definitive data showing harm at dose levels below about 100 millisievert $(100 \mathrm{mSv})$, but because much of the dose-effect data from the bomb studies related to cancer incidence appear to be linear for exposures above that level, the national and international organizations that guide public policy with respect to radiation assume a linear no-threshold model for radiation risk. By doing so, the quantitative risks of lowlevel radiation are extrapolated linearly from the high-dose data, all the way back to zero dose. Although the risk of very low dose radiation remains unproved and might, in fact, be nonexistent, the use of the linear no-threshold model reflects the conservative approach adopted by these organizations.

Using the linear model and considering the comparative risks of other potentially harmful agents in our society, an independent corporation, the National Council on Radiation Protection and Measurements (NCRP), recommends values of annual and long-term maximum permissible exposures for specific groups of individuals and for the population as a whole. ${ }^{8}$ (An explanation of radiation terms is provided in Table 1.)

NCRP recommendations serve as the basis for regulatory limits enforced by federal and state agencies responsible for administering radiation control laws on both the local and national level. The current maximum annual exposure limit is 1 $\mathrm{mSv}$ for members of the general public. ${ }^{8}$ In 1990 the Federal Aviation Administration (FAA) recognized that a considerable number of flight crew members would exceed this $1 \mathrm{mSv}$ per year limit because of their cosmic-ray exposure. The FAA first published an advisory circular ${ }^{9}$ and later a more detailed document ${ }^{10}$ classifying flight crew members as radiation workers. Shortly thereafter they published another advisory outlining an educational program to be provided by all air carriers to their crew members to make them aware of these issues. ${ }^{11}$
Table 1. Terminology: Radiation Dose And Exposure.

\begin{tabular}{|c|c|}
\hline Term & Meaning \\
\hline Radiation & $\begin{array}{l}\text { The transport of energy through space. Radia- } \\
\text { tion can be either electromagnetic or particulate }\end{array}$ \\
\hline $\begin{array}{l}\text { Electro- } \\
\text { magnetic } \\
\text { radiation }\end{array}$ & $\begin{array}{l}\text { Radiation consisting of a combined electric } \\
\text { and magnetic field that travels through space as } \\
\text { pure energy with no mass. Common examples } \\
\text { are light, radio waves, } X \text {-rays, and gamma rays }\end{array}$ \\
\hline $\begin{array}{l}\text { Particulate } \\
\text { radiation }\end{array}$ & $\begin{array}{l}\text { Radiation in the form of particles having mea- } \\
\text { surable mass. Can have electrical charge or be } \\
\text { neutral. Most common particulate radiations } \\
\text { consist of any of three atomic particles (neutrons, } \\
\text { protons, or electrons) either singly or combined }\end{array}$ \\
\hline $\begin{array}{l}\text { Radiation } \\
\text { dose }\end{array}$ & $\begin{array}{l}\text { Amount of energy transferred into material ex- } \\
\text { posed to radiation. Unit of radiation dose in the } \\
\text { SI system (le Système International d'Unités) } \\
\text { is gray (in conventional units, rad) }\end{array}$ \\
\hline Gray (Gy) & $\begin{array}{l}\text { Unit of radiation dose in SI system. } 1 \mathrm{~Gy} \\
\text { quantifies absorption of } 1 \mathrm{~J} \text { of energy by } 1 \mathrm{~kg} \text { of } \\
\text { material, ie, } 1 \mathrm{~Gy}=1 \mathrm{~J} / \mathrm{kg}\end{array}$ \\
\hline $\begin{array}{l}\text { Rad } \\
\text { (obsolete) }\end{array}$ & $\begin{array}{l}\text { Unit of radiation dose in conventional units. } 1 \\
\text { rad quantified absorption of } 100 \mathrm{ergs} \text { of energy } \\
\text { by } 1 \mathrm{~g} \text { of material, ie, } 1 \mathrm{rad}=100 \mathrm{erg} / \mathrm{g}=0.01 \\
\text { Gy; } 100 \mathrm{mrad}=1 \mathrm{mGy}\end{array}$ \\
\hline $\begin{array}{l}\text { Dose } \\
\text { equivalent }\end{array}$ & $\begin{array}{l}\text { Different types and energies of radiation pro- } \\
\text { duce differing amounts of damage when inter- } \\
\text { acting with the body. A 1-Gy dose of high- } \\
\text { energy neutrons will have a different biologic } \\
\text { effect than a 1-Gy dose of X-rays. By using an } \\
\text { appropriate modifying factor, the actual dose } \\
\text { (energy deposited per unit mass-a strict physi- } \\
\text { cal definition) can be changed to a quantity that } \\
\text { allows meaningful comparisons of biologic dam- } \\
\text { age irrespective of radiation type. Regulatory } \\
\text { limits on radiation exposure set by governmental } \\
\text { agencies are given in terms of dose equivalent. } \\
\text { The unit of radiation dose equivalent in the SI } \\
\text { system is the sievert (Sv), in conventional units } \\
\text { it was the rem. Using, for example, radiations } \\
\text { mentioned above, an absorbed dose of } 1 \text { Gy of } \\
\text { high-energy neutrons equals a dose equivalent } \\
\text { of } 20 \text { Sv. At the same absorbed dose of X-rays, } 1 \\
\text { Gy will have the dose equivalent of only } 1 \text { Sv }\end{array}$ \\
\hline Sievert (Sv) & $\begin{array}{l}\text { Unit of radiation dose equivalent in the SI } \\
\text { system }\end{array}$ \\
\hline $\begin{array}{l}\text { Rem } \\
\text { (obsolete) }\end{array}$ & $\begin{array}{l}\text { Unit of dose equivalent in conventional units, } 1 \\
\text { rem }=0.01 \mathrm{~Sv} ; 1 \mathrm{mSv}=100 \mathrm{mrem}\end{array}$ \\
\hline
\end{tabular}

\section{Dual Standard For Radiation Protection}

The regulatory limit of radiation exposure for radiation workers is 50 times greater than for members of the general public. ${ }^{8}$ The rationale for this large difference is predicated not only on the difference between the acceptability of a radiation exposure to a compensated employee compared with an innocent bystander; it is also based on several other important areas of dissimilarity. Radiation workers are legally required to be at least 18 years of age, whereas the public is comprised of all age groups including children, who might be more susceptible to harm. Employers are required to es- 
tablish ongoing health monitoring for radiation workers so that any radiation injuries can be detected early on, when there is still a good opportunity for corrective medical intervention. Finally, radiation workers must willingly accept their increased levels of risk or seek other employment.

Current federal regulations require those who are occupationally exposed to be fully educated about these risks so they can make the explicit decision that these risks are acceptable. ${ }^{12}$ Members of the public who receive their radiation exposures through releases of radioactive materials into the environment or by contact with radiation-producing machines used in medicine or industry generally have little or no choice.

The linear versus dose model of radiation effect implies that the level of acceptable risk for radiation workers is also 50 times greater than that for members of the public. For airline crew members, the maximum cosmic-ray exposure rate at airliner altitudes, coupled with the practical limitations of in-flight work hours, ensures that the doses received while flying are well within the occupational limits. The FAA recognizes, however, that the situation could be different for pregnant crew members for whom there is a recommended maximum total fetal dose of $5 \mathrm{mSv}$ distributed within the 9 months of pregnancy. This amount is about 10 times more restrictive than the adult occupational limit of $50 \mathrm{mSv}$ annually. ${ }^{10}$

\section{Specific Risk Estimates}

Inquiries to physicians about radiation risks from flying will most likely come from two categories of patient: frequent business flyers and pregnant travelers who might or might not be frequent flyers. To address the concerns of both groups, it is necessary to first understand the currently accepted quantitative values of radiation risk.

\section{Risk of Cancer to Adult Flyers}

Using the linear model, the current maximum permissible annual radiation dose to the whole body, 1 $\mathrm{mSv}$, has a 4 in 100,000 chance of producing a fatal cancer assuming the dose is delivered incrementally within the year (the risk is somewhat higher for a single exposure of this magnitude). If a member of the public was to be exposed at this level for 60 years, the risk would be 60 times as great, or 24 in 10,000. Current health statistics in the United States indicate that for the population as a whole a fatal cancer will claim the life of 2200 of every 10,000 persons. Accordingly, the current value of maximum permissible exposure predicts a worst case of 2224 cancer deaths, instead of 2200 , for 10,000 persons receiving this exposure within their lifetimes, about a 1 percent increase.

Putting this into perspective compared with other risks that are well known, the 4 in 100,000 annual cancer risk is equivalent to the risk of traveling 400 miles on a bicycle, 4 hours in a canoe, or 12,000 miles in a car, or of drinking $20 \mathrm{~L}$ of wine or 1200 cans of diet soda containing saccharin. ${ }^{13} \mathrm{~A}$ recent analysis shows that to receive a $1-\mathrm{mSv}$ exposure in a year, a business traveler would have to fly approximately 75,000 miles $(121,000 \mathrm{~km})$. It has been estimated that more than 400,000 business frequent flyers do travel at least this distance annually. Their cancer risks, as well as the risks for those who fly much less often, can be derived by scaling the 4 in 100,000 risk coefficient against the ratio of their actual flight mileage compared with the benchmark 75,000 miles. For example, a flyer traveling 18,750 miles per year would have a risk of cancer increased by a factor of 1 in 100,000, that is, multiplied by 1.00001 , each year.

\section{Risk to the Embryo or Fetus}

\section{Preconception Radiation Exposure}

There is a small risk associated with radiation exposure of sperm or ova before conception. The probability is estimated as 1.5 per $1,000,000$ for the $1-\mathrm{mSv}$ maximum permissible dose. The current incidence of genetic abnormalities in the general population is greater than 42,000 per $1,000,000$ live births. Thus the incremental risk is almost negligible for this category of exposure.

\section{Prenatal Radiation Exposure}

The risk of radiation to a developing fetus requires a complex analysis, because different effects take place at different stages of fetal development. If a high exposure occurs in the first 8 days after conception, the most likely result will be death of the embryo. At this stage of development, the embryo has not yet attached to the uterus and the brief period of pregnancy will likely go unnoticed. Most organ development begins about 9 days after conception and continues through the 7th week of pregnancy. After this time the basic structures of the body are in place and only growth occurs. It is from the 9th to the 50th day that the fetus is most 
sensitive to the effects of radiation, with the peak sensitivity occurring during the 3 rd and 4th weeks of pregnancy. If a fetus is exposed to radiation somewhat later in pregnancy, toward the end of the first trimester, the most likely effect will be on the mental development of the child. Retardation or a learning disability is associated with irradiation at that stage of pregnancy. Finally, irradiation in utero at any time is associated with an increased risk of developing childhood cancer. ${ }^{6}$

A complex calculation by the FAA, weighting the risks at each period of fetal development by the dose accumulated as a flyer travels on a regular basis throughout her pregnancy, shows the probability for fetal damage to be about 3 in 10,000 for a 1 $\mathrm{mSv}$ total exposure. ${ }^{10}$ Current statistics show that about 600 of every 10,000 children are born with abnormalities that have serious health consequences, so exposure to the maximum permissible dose of $1 \mathrm{mSv}$ could increase the number of birth defects from 600 to 603 .

Remember, however, that a $1-\mathrm{mSv}$ exposure is associated with air travel of about 75,000 miles. For a pregnant patient who expresses concern about a single visit to Europe for a vacation or a flight across the country to visit relatives, the total round-trip exposure would generally not exceed $0.1 \mathrm{mSv}$. This dose causes an incremental risk of 3 in 100,000 , ie, an increase by a factor of 1.00003 , that the exposure from that round-trip flight would cause a serious health problem for the unborn child.

\section{Fertility}

Both sperm and egg cells are sensitive to radiation. Although radiation can impair fertility, this effect requires a dose of radiation that is large enough to damage or deplete most of the reproductive cells. This endpoint is dose dependent with a threshold dose below which there is no apparent effect. At the levels encountered in flight, there will be no impairment of fertility in either men or women. The threshold dose for induction of temporary sterility in the adult testes from a single exposure is $150 \mathrm{mSv}$, for permanent sterility it is $3500 \mathrm{mSv}$. In experiments with dogs, a dose of $1.2 \mathrm{mSv} / \mathrm{d}$ has been tolerated indefinitely with no detectable effect on sperm production. The equivalent threshold dose for temporary sterility of a human ovary is $650 \mathrm{mSv}$. Permanent sterility requires at least $2500 \mathrm{mSv}$ to be received in a single exposure, which increases to $6000 \mathrm{mSv}$ if the exposure occurs with time. ${ }^{6}$

\section{Solar Flares}

Energetic solar flares, which can occur without warning, are an additional factor influencing inflight radiation exposure. A certain number of these flares result in the emission of high-energy radiation that can considerably increase the usual dose rates at airliner altitudes. Solar flares are caused by instabilities in the nuclear processes, which drive the fusion reactions that produce the sun's energy. Although as many as 10,000 solar flares occur each year, a relatively small number (usually fewer than 20) emit enough extra radiation to affect the airliner environment. When they do, however, these charged particle events can produce exposure rates that are 10 to 20 times their usual values. In other words, if the radiation-producing flare lasts as long as the flight, a single one-way trip could give as much radiation exposure to a passenger or crew member as they would ordinarily receive in 10 to 20 trips. ${ }^{14}$

The frequency of these solar particle events is very irregular, although they do correlate with the cyclical nature of sunspot activity. The number of sunspots tends to rise and fall within an approximately 11-year period. The frequency of energetic particle events follows a similar pattern. The peak of the last solar cycle occurred around 1989 and 1990. In 1989 there were 22 such events, including the largest observed in 30 years. ${ }^{15}$ In 1995 and 1996, the period of minimum solar activity, none were recorded. ${ }^{16}$ The first major particle event of the current solar cycle occurred on 7 November 1997. ${ }^{17}$ The FAA has been actively encouraging the National Oceanic and Atmospheric Administration (NOAA), which provides satellite monitoring of solar activity through their Space Weather Operations Center, to investigate the possibility of a real-time flare warning system that could be used to alert airlines. A requirement of such a system would be an associated plan for the orderly reduction in altitude of the large number of commercial aircraft that are aloft at any particular time. ${ }^{18}$

\section{Conclusions}

At present, several hundred thousand personsairline flight crew members and business frequent flyers-receive radiation exposures that actually exceed the legally permissible levels mandated for 
members of the general public and enforced by regulatory agencies responsible for radiation-producing ground-based industries. In the case of flight crew members, the airlines and the FAA consider them to be radiation workers. As such, they operate with an exposure limit that is $\mathbf{5 0}$ times greater than that allowed for members of the general public. Liability issues might lead businesses to impose a similar classification on their frequent flyer employees.

For business travelers and others who accumulate thousands of air-miles each year, the risk of harm from cosmic radiation is small, but it certainly cannot be ignored, particularly by pregnant frequent flyers who might want to plan their flight schedules to avoid exceeding the maximum recommended fetal dose. For pregnant patients planning only recreational travel, physicians can point out the minuscule radiation risk associated with exposure from a small number of flights. With regard to solar particle events, it is hoped there will soon be a mechanism from the FAA and NOAA to provide an early warning to air travelers in the case of seriously elevated radiation levels at airliner altitudes.

\section{References}

1. National Council on Radiation Protection and Measurements. Recommendations on limits for exposure to ionizing radiation: recommendations of the $\mathrm{Na}$ tional Council on Radiation Protection and Measurements. NCRP report no. 91. Bethesda, Md: The Council, 1987.

2. Friedberg W, Faulkner DN, Snyder L, Darden EB $\mathrm{Jr}$, O'Brien K. Galactic cosmic ray exposure and associated health risks for air carrier crewmembers. Aviat Space Environ Med 1989;60:1104-8.

3. Friedberg W, Faulkner DN, Snyder L, Darden EB $\mathrm{Jr}$, O'Brien K. Update on possible health effects from exposure to galactic cosmic radiation. Aviat Space Environ Med 1990;61:868.

4. United Nations, Scientific Committee on the Effects of Atomic Radiation. Annex C: biological effects of pre-natal irradiation. In: Genetic and somatic effects of ionizing radiation: 1986 report to the General Assembly, with annexes. New York: United Nations, 1986.
5. Barish RJ. Health physics concerns in commercial aviation. Health Phys 1990;59:199-204.

6. Upton AC, Stoto MA, Committee on the Biological Effects of Ionizing Radiation, National Research Council. Health effects of exposure to low levels of ionizing radiation BEIR V. Washington DC: $\mathrm{Na}$ tional Academy Press, 1990.

7. Pierce DA, Shimizu, Y, Preston DL, Vaeth M, Mabuchi K. Studies of the mortality of atomic bomb survivors. Report 12, part I. Cancer: 1950-1990. Radiat Res 1996;146:1-27.

8. National Council on Radiation Protection and Measurements. Limitation of exposure to ionizing radiation: recommendations of the National Council on Radiation Protection and Measurements. NCRP report no. 116. Bethesda, Md: The Council, 1993.

9. Radiation exposure of air carrier crewmembers, AC 120-52. Washington, DC: US Dept of Transportation, Federal Aviation Administration, 1990.

10. Friedberg W, Snyder L, Faulkner DN. Radiation exposure of air carrier crewmembers II. Federal Aviation Administration report DOT/FAAAM-92/2. Washington, DC: US Dept of Transportation, Federal Aviation Administration, Office of Aviation Medicine, 1992.

11. Crewmember training on in-flight radiation exposure. Advisory circular AC no 120-61. Washington, DC: Federal Aviation Administration, 1994.

12. US Environmental Protection Agency, Office of Radiation Programs. Radiation protection guidance to federal agencies for occupational exposure: recommendation approved by the President. Federal Register 1987;52:2822-34.

13. Wilson R. Analyzing the risks of daily life. Technol Rev 1979;10:45.

14. Barish RJ. The invisible passenger-radiation risks for people who fly. Madison, Wis: Advanced Medical Publishing, 1996.

15. Preliminary report and forecast of solar geophysical data. SESC PRF 735. Boulder, Colo: Space Environment Services Center, 1989:1-17.

16. Preliminary report and forecast of solar geophysical data. SWO PRF 1092. Boulder, Colo: Space environment Services Center, 1996:10.

17. US Department of Commerce, Space Environment Center. On-line data: gopher://solar.sec.noaa.gov/ 19/plots/proton/971107.

18. Barish RJ. Health physics and aviation: 1990-1994. Health Phys 1995;69:538-42. 